\title{
Optimization of Extrusion and Sphenronization Parameters for Tolterodine Tartrate Pellets by Design of Experiment (DoE)
}

\author{
Vijaykumar Patil ${ }^{1}$, Dr. Deepak Belsare ${ }^{2}$ \\ ${ }^{1}$ Research Scholar, Faculty of Pharmacy, Pacific Academy of Higher Education and Research University, Udaipur. \\ ${ }^{2}$ Professor Emeritus, NDMVP Samaj's College of Pharmacy, Nasik
}

\begin{abstract}
Objective: The purpose of this indicative DoE is the optimization of Screw Speed and Sphenronization Speed which may impact the final physical and chemical parameters of pellets such as aspect ratio/sphericity, PSD and dissolution which are pre-requisite for further extended release coating on immediate release pellets. From the risk assessment and Pre DoE, Aspect Ratio, Dissolution at 30 min and PSD were identified as critical quality attributes which may be potentially influenced by the factors s4ch as Screw Speed and Sphenronization Speed and their respective levels. Methods: Immediate release pellets of tolterodine were prepared and optimized by employing extrusion spheronization process. The experimental ranges chosen were based on the development experience and prior knowledge. Since the aim of DoE was to assess the impact of factors that would affect the product critical quality attributes (CQAs), a central composite design was chosen. Results: The optimized process parameters exhibited required dissolution, PSD and aspect ratio of immediate release pellets which are further required for successful extended release coating. DoE statistical analysis demonstrated the impacts of all factors (in the studied range) on the responses studied. Based on the observation suggested model for PSD below \# 25 was Linear, for PSD above \# 20-25 its Quadratic, for aspect ratio its Quadratic and for response Dissolution at 30 min its Quadratic. Conclusion: Based on the statistical analysis and considering the scientific rational product performance, it can be concluded that the Factor A (Screw Speed) and Factor B (Spheronization Speed) were the significant factors which had impact on the response dissolution, aspect ratio and PSD.
\end{abstract}

Keywords: Tolterodine tartrate, Extrusion-Spheronization, Central composite design (CCD), Dissolution, Aspect ratio, PSD

\section{Introduction}

Tolterodine, antimuscarinic (anticholinergic) agent is indicated for treating $\mathrm{OAB}$ with symptoms of urinary frequency, urgency and leakage[1, 2]. Tolterodine acts as a competitive antagonist of acetylcholine at postganglionic muscarinic receptors. Both urinary bladder contraction and salivation are mediated via cholinergic muscarinic receptors. After oral administration, tolterodine is metabolized in the liver, resulting in the formation of 5-hydroxymethyl tolterodine (5-HMT), the major pharmacologically active metabolite. 5-HMT, which exhibits an antimuscarinic activity similar to that of tolterodine, contributes significantly to the therapeutic effect. Both tolterodine and 5-HMT exhibit a high specificity for muscarinic receptors, since both show negligible activity and affinity for other neurotransmitter receptors and other potential cellular targets, such as calcium channels[3].

The International Continence Society (ICS) defines incontinence as the involuntary loss of bladder or bowel control. Urinary Incontinence (UI) is a stigmatized, underreported, under-diagnosed, under-treated condition that is erroneously thought to be a normal part of aging. One-third of men and women aged 30-70 believe that incontinence is part of aging to accept.

Information on healthy bladder function can help promote the understanding that incontinence is not a normal part of aging but a symptom of another problem. The social costs of UI are high and even mild symptoms affect social, sexual, interpersonal, and professional function.
For urge incontinence, medications known as anticholinergics/ antimuscarinics (tolterodine, oxybutynin chloride, darifenacin, fluoxetine hydrochloride, and solifenacin succinate) can prevent bladder spasms and $\mathrm{OAB}$

At the time of research, there was no alternative formulation available other than innovator which was patented and costly. The aim of the present study was to develop a formulation using simpler techniques and circumventing the technology used by the innovator product in order to have technological and commercial advantage along with benefit to society.

In the present research work tolterodine was selected for the development of an ER[4] formulation which was developed as a generic version of Detrol LA, marketed by PfizerPharmacia and Upjohn Co.

The study was directed towards the development of a novel drug delivery system based on pelletization technique and was limited to the development of a formulation which can be commercially exploited for well-being of society in general and meant for the US market in particular.

Tolterodine formulation was developed in two parts where in extrusion pelletization technique is used to develop immediate release pellets of tolterodine tartrate followed by extended release coating using wruster process.

This study was carried out using QbD approach where central composite design was used for design of experiment to optimize the extrusion spheronization parameters for 


\section{International Journal of Science and Research (IJSR) \\ ISSN (Online): 2319-7064}

Index Copernicus Value (2015): 78.96 | Impact Factor (2015): 6.391

development of immediate release pellets formulation of tolterodine.

\section{Literature Survey}

\subsection{Drug Delivery}

Humankind's efforts to confront disease dates back to early civilization. Substances taken from nature were tested and used to treat dysfunctions of physiological life processes, pain and discomfort. With the advancement of science, the active ingredients of these materials, the drugs, were identified, isolated and in many cases their mechanism of action elucidated. New drug candidates are tested even today in the quest to add increasingly effective tools against diseases.

Drug characteristics differ dramatically, even those aimed to treat the same symptoms; chemical composition, size, hydrophilicity and potency identify molecules whose function may be specific or highly complex. An increasing understanding of cellular biology at the molecular level, combined with the (decoding) of the human genome, and a technological breakthrough in the field of proteomics and DNA micro-arrays, has introduced even more applicants, like peptides and nucleic acids (gene delivery).

Drug activity is a result of molecular interaction(s) in certain cells; it is therefore easily deduced that it is necessary for the drug to reach somehow the site of action following administration (oral, intravenous, local, transdermal, etc.) at sufficient concentrations. The Scientific field dealing with this issue is known as drug delivery and has essentially the Following aim: to deliver the drug at the right place, at the right concentration for the right period of time. When this is impossible by simply selecting an appropriate administration route, or if such administration causes patient discomfort, strategies based on the association of the drug with a carrier (a drug delivery system - DDS) are an alternative1, 2. Additional motivations for such approaches include the reduction of required resources for therapy, accomplished by an increase of the drug's therapeutic index and the prevention of frequent, unpleasant or expensive treatments.

Drug delivery systems, ranging from implantable electronic devices to single polymer chains, are required to be compatible with processes in the body (biocompatibility) as well as with the drug to be delivered. DDS alter the biodistribution and pharmacokinetics of the associated drug: that is the time-dependent percentage of the administered dose in the different organs of the body. Furthermore, obstacles arising from low drug solubility, degradation (environmental or enzymatic), fast clearance rates, nonspecific toxicity, inability to cross biological barriers, just to mention a few, may be addressed by DDS2.

Overall, the challenge of increasing the therapeutic effect of drugs, with a concurrent Minimization of side effects, can be tackled through proper design and engineering of the DDS, in a case-to-case manner.

\subsection{Pellet}

\subsubsection{Pellet as a Pharmaceutical Dosage Form:}

Although the basic meaning of the word 'pellet' is 'a small ball or tube-shaped piece of Any substance', in the different branches of industry and agriculture this term is used to Indicate particles or piles of particles of various shape, size and scale, which are Produced by granulation, extrudation, pelletisation, drop-frosting ${ }^{4}$ hence forward according to pharmaceutical requirements and specialization. 'Pellet' is to refer to granuled pharmaceutical dosage form for per oral usage $^{4}$, which is characterized by $10^{-3}-10^{-4} \mathrm{~m}$ in size, nearspherical form, slightly uneven surface and Compactness approximate to that of agglomerated materials (low porosity). Thus the Advantages of the pellet as a pharmaceutical dosage form are implied in the above given Definition [5]

\subsubsection{Good Coating Properties}

The minimum scale of surface/capacity (volume) relatively Even surface and small degree of porosity from the point of view of coating - especially Film coating - is optimal both technologically (low powder formation, quick drying, Reduced proneness to agglutination) and because of the relative quantity of the coating Material; e.g. fluidization granules produced by spraying process - the structure of which can be compared to that of breadcrumbs' - are practically impossible to abrupt with reasonable quantity of coating material. In connection with good coating properties fraction toughness and abrasion hardness derived from the shape and form of the granules and the almost identical specific surface of the particles from successive batches can also be mentioned.

\subsubsection{Adjustable Active Ingredient Transmission:}

The definite specific surface derived from the near-spherical shape (form) which can reliably influenced by modifying the size of the particles and the good coating properties ensure almost infinitely adjustable active ingredient transmission and plan able active ingredient transmission profile. Regarding the latter we should think - for example - that the 'small balls' can be covered by coating different in quality and thickness, and these can be arbitrarily blended together before filling capsules or compression. In this way the ingestion of the initial and the maintaining dose can happen simultaneously and safely, alongside with the elimination of the side-effects caused by top concentration and the continuous assurance of the plasma concentration.

\subsubsection{Low Toxicological Risk}

If the coating of a retard capsule or a pellet is incomplete/imperfect or damaged a toxic dose may enter the patient's organism. However, in the capsule fillings or tablets a few (among several hundred or thousand) pellets with damaged coating do not cause significant rise of drug concentration measured in blood. Here it can be mentioned that during further production, transportation and dosing of the pellet - especially in the case of coated granules - the danger of dust formation is minimal, because the pile is practically free from powder and the particles have no sharp ends which, if fractured, could lead to powder formation (Their friability is low). 


\section{International Journal of Science and Research (IJSR) \\ ISSN (Online): 2319-7064 \\ Index Copernicus Value (2015): 78.96 | Impact Factor (2015): 6.391}

\subsubsection{Good Flowing Properties}

The relatively big volume of the particles, the shape and the Surface means good flowing properties and quick dosing ability. The significance of this Is well known in the case of high-speed rotary machines, but filling machines for hard Gelatin capsule have also reached the same speed and so glidant have to be used to Improve the usual flowing properties of the granules.

Stable unit density: In the case of the usual granules especially that of produced by Fluidization Atomization - the variable and heterogeneous distribution of the size of the particles, the fluctuating porosity of the particles, the irregular particle form cause the change of the unit density within a relatively large domain. The fluctuation of the unit density in the case of pellets is much lower, which is a great advantage at filling/charging by volume (e.g. in the matrices of tablet machines or during the process of charging into hard gelatin capsules).

\subsubsection{Aesthetic Appearance}

The pellets of various sizes and their mixtures are quite aesthetic (This is why they are filled into transparent capsules). This factor is not negligible neither from the viewpoint of market aspects, nor in the case of the psychological effect made on the patient.

\subsubsection{Adjustable Distribution of Retention Time:}

In the case of oral dosage form the pharmaceutical form basically influences the distribution time both in the gastrointestinal systems, and the time during which the given product in which part of the system stays longer (e.g. tablets usually in the stomach, pellets in the bowels).to avoid being predisposed in the favor of the subject it is necessary to list.

\subsubsection{Contradictions in Connection with Pellets:}

The scientific literature mention disadvantages as well. However, in the field of the subject the technical and technological development is so fast that those 'yesterday's' counter arguments (e.g. the procedure is rather time and energy consuming) 'today' do not hold their grounds. Sometimes natural things are mentioned as disadvantageous, for instance 'in order to produce pellets new equipment are needed to be obtained, which is costly'. This is true, of course,although not specifically for pellet manufacturing, but nearly in all when the aim is to improve formulation. Besides it is always hard to compare things by quantity measures that differ in quality. The contradiction can be stated shortly and simply: pellets are not to be produced when there are no advantages whatsoever compared to the simpler formulation or, if the expenses incurred are not in scale with the emerging advantages and cannot be realized in the price.

\subsection{Pelletization Technique [6, 7]:}

1. Extrusion - Spheronization Technique or Wet Mass Extrusion.

2. Hot Melt Extrusion Process.

3. Layer Building Method.

4. Globulation or Droplet Formation.

5. Cryopelletization.

\author{
6. Balling. \\ 7. Freeze Pelletization. \\ 8. Compression.
}

\subsection{Extrusion - Spheronization:}

ES is the most convenient method used in the pharmaceutical industry to make uniform sized spheroids. It was first reported by Reynolds, Conine and Hadley in 1970 [8]

It is a multistep process involving four steps namely mixing, granulation, extrusion, spheronization and finally drying of prepared pellets [9]. In the first step, powders are dry mixed to obtain uniform dispersion. It is usually carried out in same mixer used for granulation. The uniformity of dry mix has a significant effect on the quality of spherical particles produced.

In the next step, wet mass of sufficient plasticity is produced from the powder dispersion. It is similar to conventional granulation technique used for compressed products. The most commonly used granulator is planetary mixer or sigma blade mixer or high shear mixer and Hobart mixer.

High shear mixer brings in high amount of energy into the wet mass which is transformed into heat and causes evaporation of granulation fluid. This changes the extrusion behavior of the wet mass. This can be avoided by cooling the granulation bowl [10-16].

The next step is extrusion. It consists of shaping the wet mass into long rods termed as 'extrudates'. It is considered as specialized wet granulation technique as well as integral part of overall spheronization process. The extrusion process is used not only in the pharmaceutical industry but also in the food, ceramic and polymer industries. The extrusion process is currently used as an alternative method for the manufacture of completely water-soluble tablets [17].

In this method, the wet mass is forced through the opening of dies and shaped into small cylindrical particles having uniform diameter. The extrudate particles break at similar lengths under their own weight. The extrudate must have enough plasticity to deform. If it is more, the particles adhere together when collected or rolled in the spheronizer. This operation is the major contributing factor in the final particle size of the pellets. The diameter of the extruder screen opening directly controls the diameter of the extrudate $[18,19]$.

There is great variety of extruders. Extruders are classified based on the extrusion zone. In axial extruders, the wet mass is conveyed and it is forced through a flat perforated plate and extruded in same plane. In radial extruders, the wet mass is transferred perpendicular to the extrusion plane. The screw and gravity extruders are used mainly for development and manufacturing procedure.

The main difference between screw and gravity extruder is that before extrusion less compression force is applied in gravity feed extruder [20,21]. 


\section{International Journal of Science and Research (IJSR) \\ ISSN (Online): 2319-7064}

Index Copernicus Value (2015): 78.96 | Impact Factor (2015): 6.391

The next step is spheronization. Spheronization method was first introduced by Nakahara in 1964. It is a single step process in which the extruded particles refine and form uniform sized spheres. The formation of pellets depends on the formulation of extrudates. The equipment used is spheronizer, also called as merumerizer, is simple equipment consisting of a bowl with fixed side walls and fast rotating bottom plate or disk. The sphericity of the pellets depends on the frictional forces applied i.e. force generated by particle-to-particle and particle-to-equipment interaction. The spheronization of a product usually takes $2-10 \mathrm{mins}$ [2225]

Drying is the final step in extrusion-spheronization method. In this step, prepared pellets are dried at room temperature or at elevated temperature in a tray drier/oven or in fluidized bed drier. The choice of the drier is mainly based on particle properties desired.

\section{Applications:}

1) Production of controlled release reservoir system and sustain-release pellets.

2) Useful in masking the bitter taste of an active drug and used in enhancing dissolution rates for poorly water soluble drugs.

3) Improves dissolution and bioavailability of drug by forming solid dispersions or solid solutions.

\section{Materials and Methods}

Chemicals and reagents

Tolterodine was procured from Cipla, Mumbai, India; hypromellose 2910 USP was procured from Colorcon India Ltd, microcrystalline cellulose and mannitol were procured from Signet chemical, Mumbai, India.

\section{Equipments}

Rapid mixer granulator (RMG) (Gansons-31), Gansons Ltd, Mumbai, India; extruder-spherodizer (USPH-60), Umang Pharmatech, India.

\section{Methods}

Preparation of immediate release core pellets of tolterodine

Trials to formulate the core immediate release pellets of tolterodine(table 1).

Table 1: Composition of immediate release pellets of tolterodine

\begin{tabular}{|l|c|c|}
\hline Ingredients & Function & composition \\
\hline Tolterodine tartrate & Active & 4 \\
\hline Microcrystalline cellulose & Diluent & 100 \\
\hline Mannitol & Diluent & 28 \\
\hline Hypromellose, 2910 & Binder & 10 \\
\hline Purified water & Solvent & qs \\
\hline Average weight(mg) & & $\mathbf{1 4 2}$ \\
\hline
\end{tabular}

Extrusion and spheronisation was followed where tolterodine, microcrystalline cellulose and mannitol were sifted through 30 mesh sieve. The resultant material was mixed in a RMG for 10 min. Methocel E5 was dissolved in water and the dry mix was granulated with this binder solution which was followed by extrusion, spheronization and drying.

Table 2: Design Summary

\begin{tabular}{|c|c|c|c|c|}
\hline \multicolumn{2}{|c|}{ Design for formulation Component } & \multicolumn{2}{|c|}{ Optimization Design } \\
\hline \multicolumn{2}{|c|}{ Design } & $\begin{array}{c}\text { 4 factorial points + 3 Centre } \\
\text { Points + 6 axial points }\end{array}$ \\
\cline { 4 - 5 } \multicolumn{2}{|c|}{ Factors } & Unit & \multicolumn{2}{|c|}{ Level } \\
\cline { 4 - 5 } A & Screw Speed & RPM & 20 & 60 \\
\hline B & $\begin{array}{c}\text { Sphenronization } \\
\text { Speed }\end{array}$ & RPM & 200 & 600 \\
\hline
\end{tabular}

Table 3: Design Layout

\begin{tabular}{|c|c|c|c|c|}
\hline \multirow{3}{*}{ Standard } & \multirow{2}{*}{ Run } & \multirow{2}{*}{$\begin{array}{c}\text { Space } \\
\text { Type }\end{array}$} & A:Screw Speed & $\begin{array}{c}\text { B:Sphenronization } \\
\text { Speed }\end{array}$ \\
\cline { 4 - 5 } & & & RPM & RPM \\
\hline 2 & 1 & Factorial & 60 & 200 \\
\hline 7 & 2 & Axial & 40 & 200 \\
\hline 3 & 3 & Factorial & 20 & 600 \\
\hline 11 & 4 & Center & 40 & 400 \\
\hline 4 & 5 & Factorial & 60 & 600 \\
\hline 10 & 6 & Center & 40 & 400 \\
\hline 1 & 7 & Factorial & 20 & 200 \\
\hline 12 & 8 & Center & 40 & 400 \\
\hline 6 & 9 & Axial & 60 & 400 \\
\hline 5 & 10 & Axial & 20 & 400 \\
\hline 13 & 11 & Center & 40 & 400 \\
\hline 9 & 12 & Center & 40 & 400 \\
\hline 8 & 13 & Axial & 40 & 600 \\
\hline
\end{tabular}

\section{Evaluation of pellets}

The pellets of all the batches were evaluated for dissolution, particle size and aspect ratio.

Table 4: Design Summary

\begin{tabular}{|c|c|c|c|}
\hline Response & Name & Units & Acceptance criteria \\
\hline R1 & Aspect Ratio & - & 0.95 to 1.05 \\
\hline R2 & Dissolution at 30 min & $\%$ & 85 to 95 \\
\hline R3 & PSD Above \#20 & $\%$ & $5-10$ \\
\hline R4 & PSD \# 20-25 & $\%$ & $85-100$ \\
\hline R5 & PSD below \#25 & $\%$ & $5-10$ \\
\hline
\end{tabular}

\section{Results / Discussion}




\section{International Journal of Science and Research (IJSR) \\ ISSN (Online): 2319-7064}

Index Copernicus Value (2015): 78.96 | Impact Factor (2015): 6.391

Table 5: Design Layout summary table with outcome

\begin{tabular}{|c|c|c|c|c|c|c|c|c|c|}
\hline Standard & Run & Space & Factor 1 & Factor 2 & Response 1 & Response 2 & Response 3 & Response 4 & Response 5 \\
\cline { 3 - 11 } & & & $\begin{array}{c}\text { A:Screw } \\
\text { Speed }\end{array}$ & $\begin{array}{c}\text { B:Sphenroni } \\
\text { zation Speed }\end{array}$ & Aspect Ratio & $\begin{array}{c}\text { Dissolution } \\
\text { at 30 min }\end{array}$ & $\begin{array}{c}\text { PSD Above } \\
\text { \#20 }\end{array}$ & PSD \# 20-25 & $\begin{array}{c}\text { PSD Below\# } \\
25\end{array}$ \\
\cline { 3 - 11 } & & RPM & RPM & & $\%$ & $\%$ & $\%$ & $\%$ \\
\hline 2 & 1 & Factorial & 60 & 200 & 0.72 & 84 & 10 & 88 & 2 \\
\hline 7 & 2 & Axial & 40 & 200 & 0.79 & 85 & 13 & 84 & 3 \\
\hline 3 & 3 & Factorial & 20 & 600 & 1.2 & 92 & 2 & 88 & 10 \\
\hline 11 & 4 & Center & 40 & 400 & 0.89 & 84 & 6 & 90 & 4 \\
\hline 4 & 5 & Factorial & 60 & 600 & 1.2 & 92 & 3 & 84 & 13 \\
\hline 10 & 6 & Center & 40 & 400 & 0.87 & 84 & 8 & 87 & 5 \\
\hline 1 & 7 & Factorial & 20 & 200 & 0.78 & 89 & 15 & 81 & 4 \\
\hline 12 & 8 & Center & 40 & 400 & 0.89 & 85 & 5 & 91 & 4 \\
\hline 6 & 9 & Axial & 60 & 400 & 0.85 & 95 & 5 & 90 & 5 \\
\hline 5 & 10 & Axial & 20 & 400 & 0.9 & 95 & 7 & 88 & 5 \\
\hline 13 & 11 & Center & 40 & 400 & 0.88 & 85 & 8 & 87 & 5 \\
\hline 9 & 12 & Center & 40 & 400 & 0.87 & 91 & 6 & 85 & 9 \\
\hline 8 & 13 & Axial & 40 & 600 & 1.3 & 91 & 4 & 81 & 15 \\
\hline
\end{tabular}

\section{Response 1: Aspect Ratio}

Table 6: Summary of Model selection

\begin{tabular}{|c|c|c|c|c|c|}
\hline \multirow{2}{*}{ Source } & Sequential & Lack of Fit & Adjusted & Predicted & \\
\cline { 2 - 6 } & $\mathrm{p}$-value & $\mathrm{p}$-value & R-Squared & R-Squared & \\
\hline Linear & 0.000059 & 0.000308 & 0.828625 & 0.748851 & \\
\hline 2FI & 0.709164 & 0.000233 & 0.812668 & 0.64806 & \\
\hline Quadratic & 0.000179 & 0.013486 & 0.979516 & 0.912526 & Suggested \\
\hline Cubic & 0.42939 & 0.0057 & 0.97955 & 0.127889 & Aliased \\
\hline
\end{tabular}

Suggested model for response Aspect Ratio is Quadratic.

Table 7: ANOVA for Aspect Ratio

ANOVA for Response Surface Quadratic model

\begin{tabular}{|c|c|c|c|c|c|c|}
\hline \multicolumn{7}{|c|}{ ANOVA for Response Surface Quadratic model } \\
\hline \multicolumn{7}{|c|}{ Analysis of variance table [Partial sum of squares - Type III] } \\
\hline Source & $\begin{array}{c}\text { Sum of } \\
\text { Squares }\end{array}$ & Degree of freedom & $\begin{array}{c}\text { Mean } \\
\text { Square }\end{array}$ & $\begin{array}{c}\text { F } \\
\text { Value }\end{array}$ & $\begin{array}{c}\text { p-value } \\
\text { Prob> F }\end{array}$ & \\
\hline Model & 0.3843 & 5 & 0.0769 & 115.7629 & 0.0000 & Significant \\
\hline A-Screw Speed & 0.0020 & 1 & 0.0020 & 3.0377 & 0.1249 & \\
\hline B-Sphenronization Speed & 0.3314 & 1 & 0.3314 & 499.1149 & 0.0000 & \\
\hline $\mathrm{AB}$ & 0.0009 & 1 & 0.0009 & 1.3557 & 0.2824 & \\
\hline $\mathrm{A}^{\wedge} 2$ & 0.0037 & 1 & 0.0037 & 5.5059 & 0.0514 & \\
\hline $\mathrm{B}^{\wedge}$ & 0.0493 & 1 & 0.0493 & 74.2796 & 0.0001 & \\
\hline Residual & 0.0046 & 7 & 0.0007 & & & \\
\hline Lack of Fit & 0.0042 & 3 & 0.0014 & 14.1571 & 0.0135 & Significant \\
\hline Pure Error & 0.0004 & 4 & 0.0001 & & & \\
\hline Cor Total & 0.3889 & 12 & & & & \\
\hline
\end{tabular}

The Model F-value of 115.76 implies the model is significant. There is only a $0.01 \%$ chance that an F-value this large could occur due to noise. Values of "Prob > F" less than 0.0500 indicate model terms are significant. In this case $B, B^{2}$ are significant model terms. Values greater than 0.1000 indicate the model terms are not significant. The "Lack of Fit F-value" of 14.16 implies the Lack of Fit is significant. There is only a $1.35 \%$ chance that a "Lack of Fit F-value" this large could occur due to noise.

\begin{tabular}{|c|c|c|c|}
\hline Std. Dev. & 0.0258 & R-Squared & 0.9881 \\
\hline Mean & 0.9338 & Adj R-Squared & 0.9795 \\
\hline C.V. \% & 2.7591 & Pred R-Squared & 0.9125 \\
\hline $\begin{array}{c}\text { PRESS (pewdicted } \\
\text { residual sum of square) }\end{array}$ & 0.0340 & Adeq Precision & 30.8330 \\
\hline
\end{tabular}

\begin{tabular}{|c|c|}
\hline \multicolumn{2}{|c|}{ Final Equation in Terms of Coded Factors: } \\
\hline Aspect Ratio & $=$ \\
\hline 0.88897 & \\
\hline-0.01833 & $* \mathrm{~A}$ \\
\hline 0.23500 & $* \mathrm{~B}$ \\
\hline 0.01500 & $* \mathrm{AB}$ \\
\hline-0.03638 & $* \mathrm{~A}^{\wedge} 2$ \\
\hline 0.13362 & $* \mathrm{~B}^{\wedge} 2$ \\
\hline
\end{tabular}

\begin{tabular}{|c|c|}
\hline \multicolumn{2}{|c|}{ Final Equation in Terms of Actual Factors: } \\
\hline Aspect Ratio & $=$ \\
\hline 0.904598 & $*$ Screw Speed \\
\hline 0.004859 & $*$ Sphenronization Speed \\
\hline-0.00165 & $*$ Screw Speed ${ }^{\wedge} 2$ \\
\hline $3.75 \mathrm{E}-06$ & $*$ Screw Speed $*$ Sphenronization Speed \\
\hline$-9.1 \mathrm{E}-05$ & $*$ Sphenronization Speed 2 \\
\hline $3.34 \mathrm{E}-06$ & \\
\hline
\end{tabular}

\section{Volume 6 Issue 7, July 2017 www.ijsr.net}




\section{International Journal of Science and Research (IJSR) \\ ISSN (Online): 2319-7064}

Index Copernicus Value (2015): 78.96 | Impact Factor (2015): 6.391
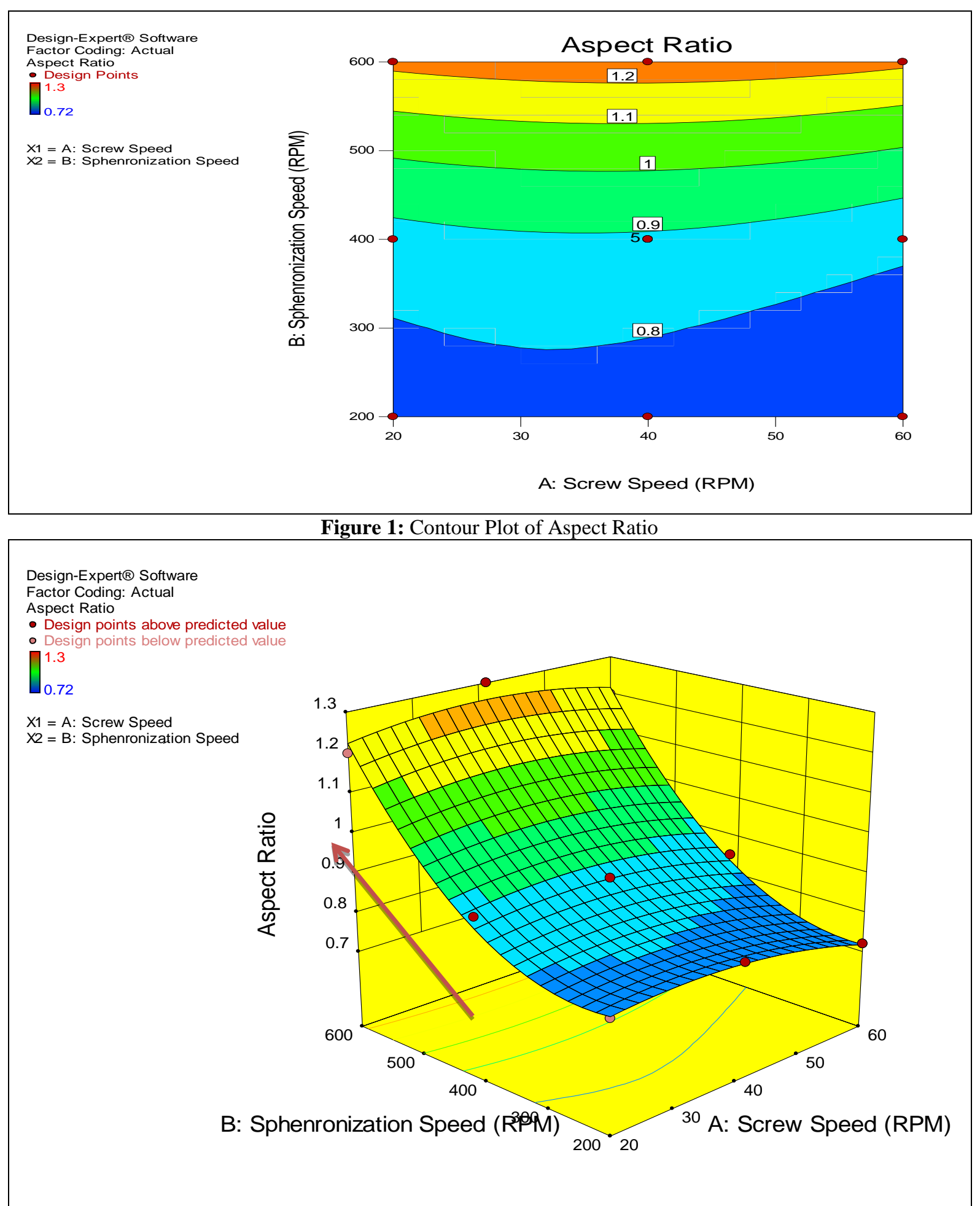

Figure 2: 3 D Plot of Aspect Ratio

DoE statistical analysis demonstrated that the impact of all factors (in the studied range) on the response studied was significant. Based on the observation suggested model for aspect ratio is Quadratic.

The Contour plot and $3 \mathrm{D}$ plot showing impact of factor A (Screw Speed) and Factor B (Spheronization speed). Although model is showing Quadratic relationship, but
ANOVA and Contour plot showing Spheronization speed is main impacting factor on the response aspect ratio. Aspect ratio depicts linear relationship i.e. as the spheronization speed increases the aspect ratio increases. Also it was observed from the data that aspect ratio throughout the studied ranges is 0.72 to 1.0 i.e. near to 1 which is required.

\section{Response 2: Dissolution at $30 \mathrm{~min}$}


International Journal of Science and Research (IJSR)

ISSN (Online): 2319-7064

Index Copernicus Value (2015): 78.96 | Impact Factor (2015): 6.391

Table 8: Summary of Model selection for dissolution

\begin{tabular}{|l|c|c|c|c|c|}
\hline \multicolumn{6}{|c|}{ Summary (detailed tables shown below) } \\
\hline & Sequential & Lack of Fit & Adjusted & Predicted & \\
\hline Source & p-value & p-value & R-Squared & R-Squared & \\
\hline Linear & 0.255425 & 0.194311 & 0.086657 & -0.17936 & \\
\hline 2FI & 0.568413 & 0.162963 & 0.023213 & -0.15898 & \\
\hline Quadratic & 0.089581 & 0.294534 & 0.369657 & -0.68872 & Suggested \\
\hline Cubic & 0.934108 & 0.088787 & 0.141256 & -22.3516 & Aliased \\
\hline
\end{tabular}

Suggested model for response Dissolution at $30 \mathrm{~min}$ is Quadratic.

Table 9: ANOVA for Dissolution at $30 \mathrm{Min}$

\begin{tabular}{|c|c|c|c|c|c|c|}
\hline \multicolumn{7}{|c|}{ ANOVA for Response Surface Reduced Quadratic model } \\
\hline \multicolumn{7}{|c|}{ Analysis of variance table [Partial sum of squares - Type III] } \\
\hline Source & $\begin{array}{l}\text { Sum of } \\
\text { Squares }\end{array}$ & Degree of freedom & $\begin{array}{l}\text { Mean } \\
\text { Square }\end{array}$ & $\begin{array}{c}\mathrm{F} \\
\text { Value }\end{array}$ & $\begin{array}{l}\text { p-value } \\
\text { Prob> F }\end{array}$ & \\
\hline Model & 120.70 & 2 & 60.3480 & 6.1341 & 0.018263 & Significant \\
\hline B-Sphenronization Speed & 48.17 & 1 & 48.1667 & 4.8959 & 0.051328 & \\
\hline $\mathrm{A}^{\wedge} 2$ & 72.53 & 1 & 72.5293 & 7.3723 & 0.021739 & \\
\hline Residual & 98.38 & 10 & 9.8381 & & & \\
\hline Lack of Fit & 63.58 & 6 & 10.5968 & 1.2180 & 0.443629 & Not Significant \\
\hline Pure Error & 34.80 & 4 & 8.7000 & & & \\
\hline Cor Total & 219.08 & 12 & & & & \\
\hline
\end{tabular}

The Model F-value of 6.13 implies the model is significant. There is only a $1.83 \%$ chance that an F-value this large could occur due to noise. Values of "Prob > F" less than 0.0500 indicate model terms are significant. In this case $\mathrm{A}^{2}$ is a significant model term. Values greater than 0.1000 indicate the model terms are not significant. The "Lack of Fit F-value" of 1.22 implies the Lack of Fit is not significant relative to the pure error. There is a $44.36 \%$ chance that a "Lack of Fit F-value" this large could occur due to noise.

\begin{tabular}{|l|l|l|l|}
\hline Std. Dev. & 3.1366 & R-Squared & 0.5509 \\
\hline Mean & 88.6154 & Adj R-Squared & 0.4611 \\
\hline C.V. \% & 3.5395 & Pred R-Squared & 0.2509 \\
\hline PRESS & 164.1012 & Adeq Precision & 6.9054 \\
\hline
\end{tabular}

\begin{tabular}{|c|c|}
\hline \multicolumn{2}{|c|}{ Final Equation in Terms of Coded Factors: } \\
\hline Dissolution at $30 \mathrm{~min}$ & $=$ \\
\hline 86.4286 & \\
\hline 2.8333 & $* \mathrm{~B}$ \\
\hline 4.7381 & $* \mathrm{~A}^{\wedge} 2$ \\
\hline
\end{tabular}

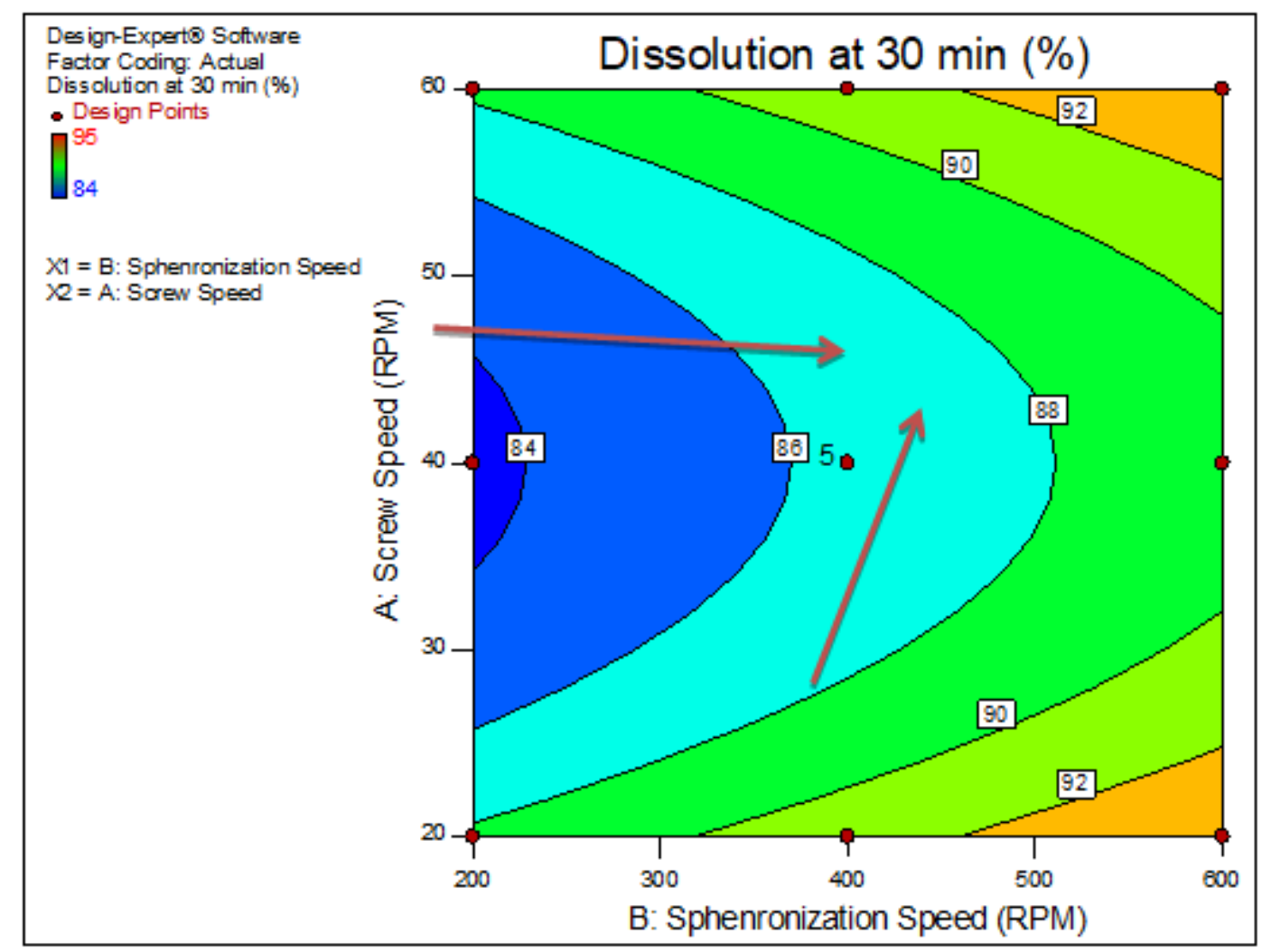

Figure 3: Contour plot of Dissolution at $30 \mathrm{Min}$ 


\section{International Journal of Science and Research (IJSR) \\ ISSN (Online): 2319-7064}

Index Copernicus Value (2015): 78.96 | Impact Factor (2015): 6.391

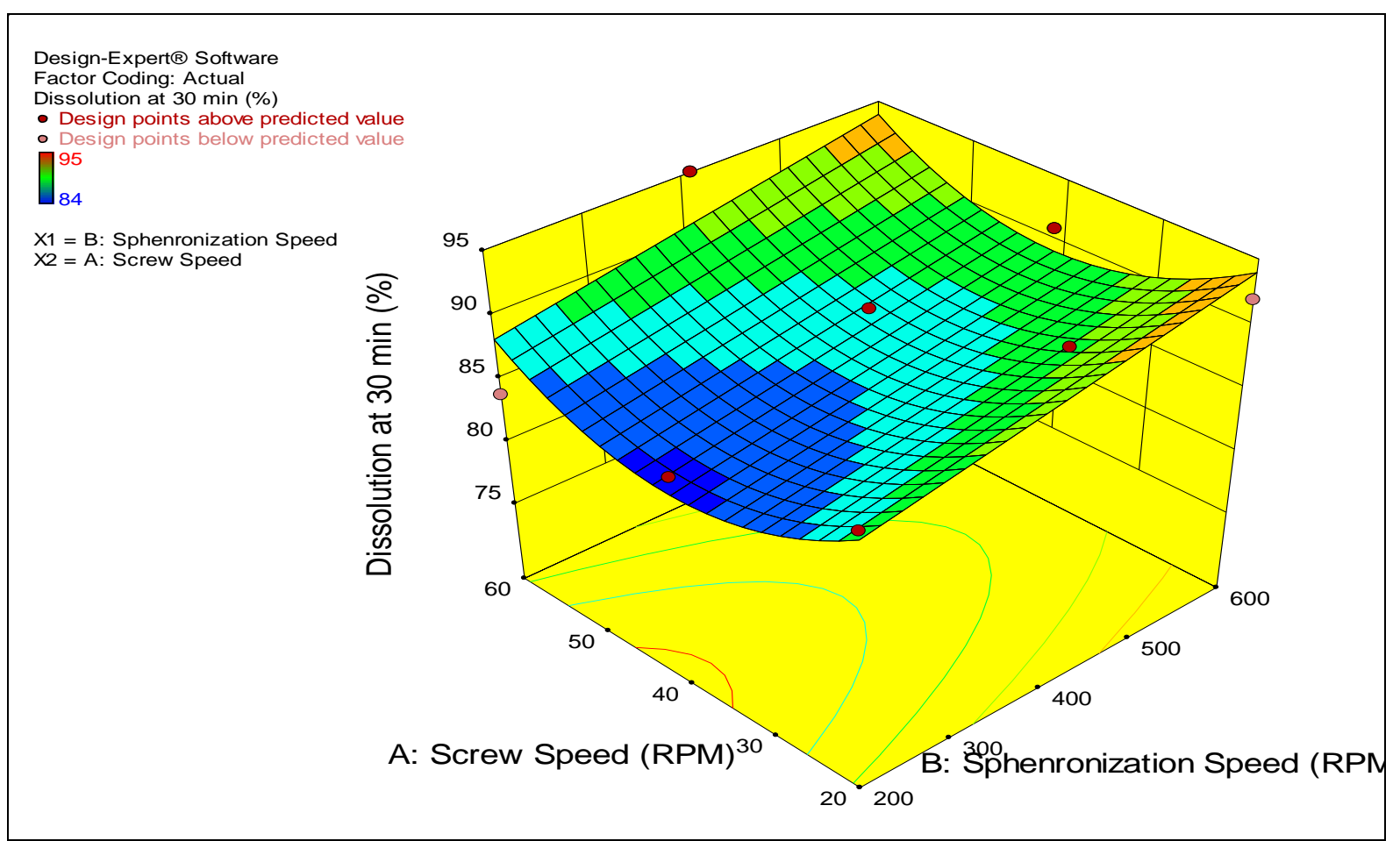

Figure 4: 3 D plot of Dissolution at 30 Min

DoE statistical analysis demonstrated that the impact of all factors (in the studied range) on the response studied was significant. Based on the observation suggested model for dissolution is Quadratic. The Contour plot and 3 D plot showing impact of factor A (Screw Speed) and Factor B (Spheronization speed). The Spheronization speed and screw speed showing Quadratic relationship on the response
Dissolution i.e. as the spheronization speed and screw speed increases the Dissolution increases. Also it was observed from the data that Dissolution throughout the studied ranges is $84.0 \%$ to $95.0 \%$ which is well within the defined limit.

Response 3: Particle Size above \#20

Table 10: Summary of Model selection for particle size above \#20

\begin{tabular}{|l|c|c|c|c|c|}
\hline \multicolumn{7}{|l|}{ Summary (detailed tables shown below) } \\
\hline & Sequential & Lack of Fit & Adjusted & Predicted & \\
\hline Source & p-value & p-value & R-Squared & R-Squared & \\
\hline Linear & $6.37 \mathrm{E}-05$ & 0.332169 & 0.826193 & 0.710037 & \\
\hline 2FI & 0.049579 & 0.53443 & 0.877088 & 0.833424 & Suggested \\
\hline Quadratic & 0.079517 & 0.966256 & 0.923337 & 0.91424 & \\
\hline Cubic & 0.894517 & 0.816639 & 0.897352 & 0.863478 & Aliased \\
\hline
\end{tabular}

Suggested model for response PSD \#20 min is 2 Factorial interactions (2FI).

Table 11: ANOVA for particle size above \#20

\begin{tabular}{|l|c|c|c|c|c|c|}
\hline \multicolumn{7}{|l|}{ ANOVA for Response Surface 2FI model } \\
\hline Analysis of variance table [Partial sum of squares - Type III] & $\begin{array}{c}\text { Sum of } \\
\text { Squares }\end{array}$ & Degree of freedom & $\begin{array}{c}\text { Mean } \\
\text { Square }\end{array}$ & $\begin{array}{c}\text { F } \\
\text { Value }\end{array}$ & $\begin{array}{c}\text { p-value } \\
\text { Prob> F }\end{array}$ & \\
\hline Model & 155.17 & 3 & 51.72 & 29.5435 & 0.0001 & Significant \\
\hline A-Screw Speed & 6.00 & 1 & 6.00 & 3.4272 & 0.0972 & \\
\hline B-Sphenronization Speed & 140.17 & 1 & 140.17 & 80.0627 & 0.0000 & \\
\hline AB & 9.00 & 1 & 9.00 & 5.1408 & 0.0496 & \\
\hline Residual & 15.76 & 9 & 1.75 & & & \\
\hline Lack of Fit & 8.56 & 5 & 1.71 & 0.9507 & 0.5344 & Not significant \\
\hline Pure Error & 7.20 & 4 & 1.80 & & & \\
\hline Cor Total & 170.92 & 12 & & & & \\
\hline
\end{tabular}

The Model F-value of 29.54 implies the model is significant. There is only a $0.01 \%$ chance that an F-value this large could occur due to noise.Values of "Prob > F" less than 0.0500 indicate model terms are significant. In this case $\mathrm{B}$, $\mathrm{AB}$ are significant model terms. Values greater than 0.1000 indicate the model terms are not significant. The "Lack of Fit F-value" of 0.95 implies the Lack of Fit is not significant relative to the pure error. There is a $53.44 \%$ chance that a "Lack of Fit F-value" this large could occur due to noise. 
International Journal of Science and Research (IJSR)

ISSN (Online): 2319-7064

Index Copernicus Value (2015): 78.96 | Impact Factor (2015): 6.391

\begin{tabular}{|l|l|l|l|}
\hline Std. Dev. & 1.3231 & R-Squared & 0.9078 \\
\hline Mean & 7.0769 & Adj R-Squared & 0.8771 \\
\hline C.V. \% & 18.6966 & Pred R-Squared & 0.8334 \\
\hline PRESS & 28.4717 & Adeq Precision & 17.2582 \\
\hline
\end{tabular}

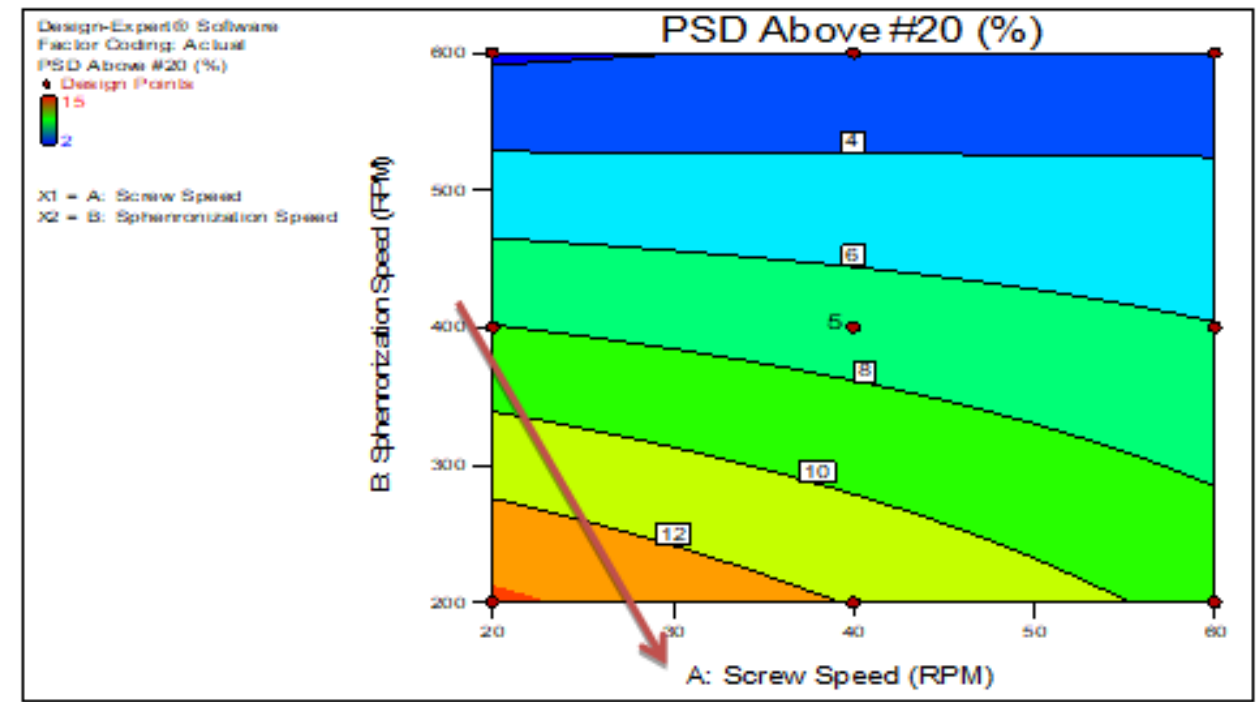

Figure 5: Particle Size Distribution above \# 20

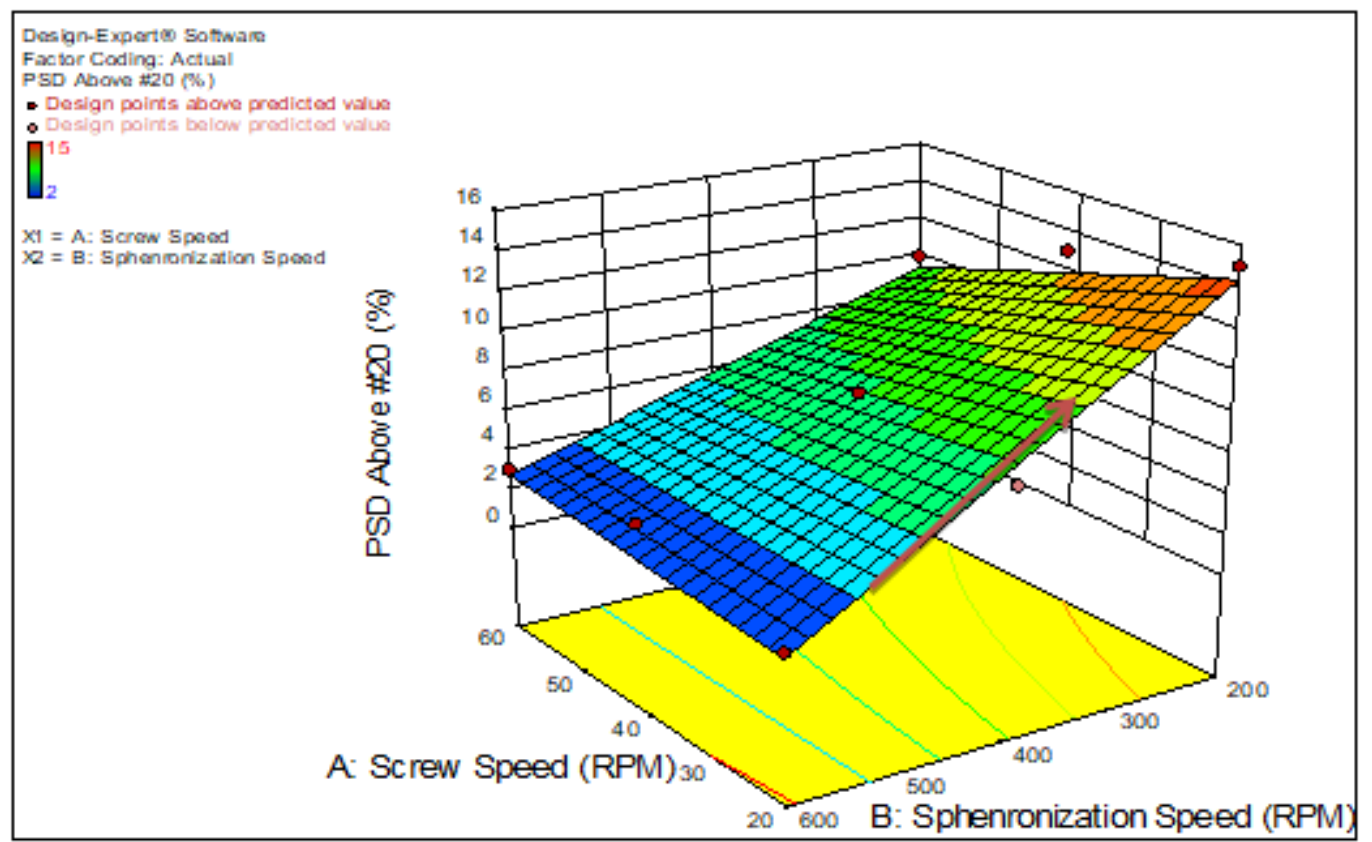

Figure 6: 3 D Plot of Particle Size distribution above \# 20

DoE statistical analysis demonstrated that the impact of all factors (in the studied range) on the response studied was significant. Based on the observation suggested model for PSD above \# 20 are 2 Factorial interactions. The Contour plot and 3 D plot showing impact of Factor B (Spheronization speed). The Spheronization speed and screw speed showing slightly 2 factorial interactions on the response Particle Size distribution above \# 20 i.e. as the spheronization speed and screw speed increases the PSD above \# 20 increases, that might be due to agglomeration of fine particles at high speed.

Response 4: Particle Size Distribution between \# 20-25

Table 12: Summary of Model selection for particle size between \#20-25

\begin{tabular}{|c|c|c|c|c|c|}
\hline \multicolumn{5}{|c|}{ Summary (detailed tables shown below) } \\
\hline & Sequential & Lack of Fit & Adjusted & Predicted & \\
\hline Source & p-value & p-value & R-Squared & R-Squared & -0.8691 \\
\hline Linear & 0.8466 & 0.1732 & -0.1607 & -0.5562 & \\
\hline 2FI & 0.1209 & 0.2207 & 0.0273 & 0.0646 & Suggested \\
\hline Quadratic & 0.0266 & 0.7039 & 0.5561 & -1.2044 & Aliased \\
\hline Cubic & 0.5593 & 0.5849 & 0.5074 & \\
\hline
\end{tabular}




\section{International Journal of Science and Research (IJSR) \\ ISSN (Online): 2319-7064 \\ Index Copernicus Value (2015): 78.96 | Impact Factor (2015): 6.391}

Suggested model for response PSD \#20-25 min is Quadratic.

Table 13: ANOVA for particle size between \#20-25

\begin{tabular}{|c|c|c|c|c|c|c|}
\hline \multicolumn{7}{|c|}{ ANOVA for Response Surface Quadratic model } \\
\hline \multicolumn{7}{|c|}{ Analysis of variance table [Partial sum of squares - Type III] } \\
\hline Source & $\begin{array}{c}\text { Sum of } \\
\text { Squares }\end{array}$ & $\begin{array}{c}\text { Degree of } \\
\text { freedom }\end{array}$ & $\begin{array}{c}\text { Mean } \\
\text { Square }\end{array}$ & $\begin{array}{c}\text { F } \\
\text { Value }\end{array}$ & $\begin{array}{c}\text { p-value } \\
\text { Prob> F }\end{array}$ & \\
\hline Model & 94.2854 & 5 & 18.8571 & 4.0066 & 0.04899 & significant \\
\hline A-Screw Speed & 4.1667 & 1 & 4.1667 & 0.8853 & 0.37808 & \\
\hline B-Sphenronization Speed & 0.0000 & 1 & 0.0000 & 0.0000 & 1.00000 & \\
\hline $\mathrm{AB}$ & 30.2500 & 1 & 30.2500 & 6.4273 & 0.03894 & \\
\hline $\mathrm{A}^{\wedge} 2$ & 9.3998 & 1 & 9.3998 & 1.9972 & 0.20048 & \\
\hline $\mathrm{B}^{\wedge} 2$ & 59.8522 & 1 & 59.8522 & 12.7170 & 0.00914 & \\
\hline Residual & 32.9454 & 7 & 4.7065 & & & \\
\hline Lack of Fit & 8.9454 & 3 & 2.9818 & 0.4970 & 0.70391 & not significant \\
\hline Pure Error & 24.0000 & 4 & 6.0000 & & & \\
\hline Cor Total & 127.2308 & 12 & & & & \\
\hline \multicolumn{7}{|l|}{} \\
\hline
\end{tabular}

The Model F-value of 4.01 implies the model is significant. There is only a $4.90 \%$ chance that an F-value this large could occur due to noise.Values of "Prob > F" less than 0.0500 indicate model terms are significant. In this case AB, $\mathrm{B}^{2}$ are significant model terms. Values greater than 0.1000 indicate the model terms are not significant. The "Lack of Fit F-value" of 0.50 implies the Lack of Fit is not significant relative to the pure error. There is a $70.39 \%$ chance that a "Lack of Fit F-value" this large could occur due to noise.

\begin{tabular}{|l|l|l|l|}
\hline Std. Dev. & 2.1694 & R-Squared & 0.7411 \\
\hline Mean & 86.4615 & Adj R-Squared & 0.5561 \\
\hline C.V. $\%$ & 2.5091 & Pred R-Squared & 0.0646 \\
\hline PRESS & 119.0112 & Adeq Precision & 6.1552 \\
\hline
\end{tabular}

\begin{tabular}{|c|c|}
\hline PSD \# 20-25 & $=$ \\
\hline 87.75862 & \\
\hline 0.833333 & $* \mathrm{~A}$ \\
\hline 0 & $* \mathrm{~B}$ \\
\hline-2.75 & $* \mathrm{AB}$ \\
\hline 1.844828 & $* \mathrm{~A}^{\wedge} 2$ \\
\hline-4.65517 & $* \mathrm{~B}^{\wedge} 2$ \\
\hline
\end{tabular}

Final Equation in Terms of Coded Factors:

\begin{tabular}{|c|c|}
\hline \multicolumn{2}{|c|}{ Final Equation in Terms of Actual Factors: } \\
\hline PSD \# 20-25 & $=$ \\
\hline 63.85057 & $*$ Screw Speed \\
\hline-0.0523 & $*$ Sphenronization Speed \\
\hline 0.120603 & $*$ Screw Speed ${ }^{\wedge} 2$ \\
\hline-0.00069 & $*$ Screw Speed $*$ Spheed \\
\hline 0.004612 & $*$ Sphenronization Speed 2 \\
\hline-0.00012 & S 2 \\
\hline
\end{tabular}

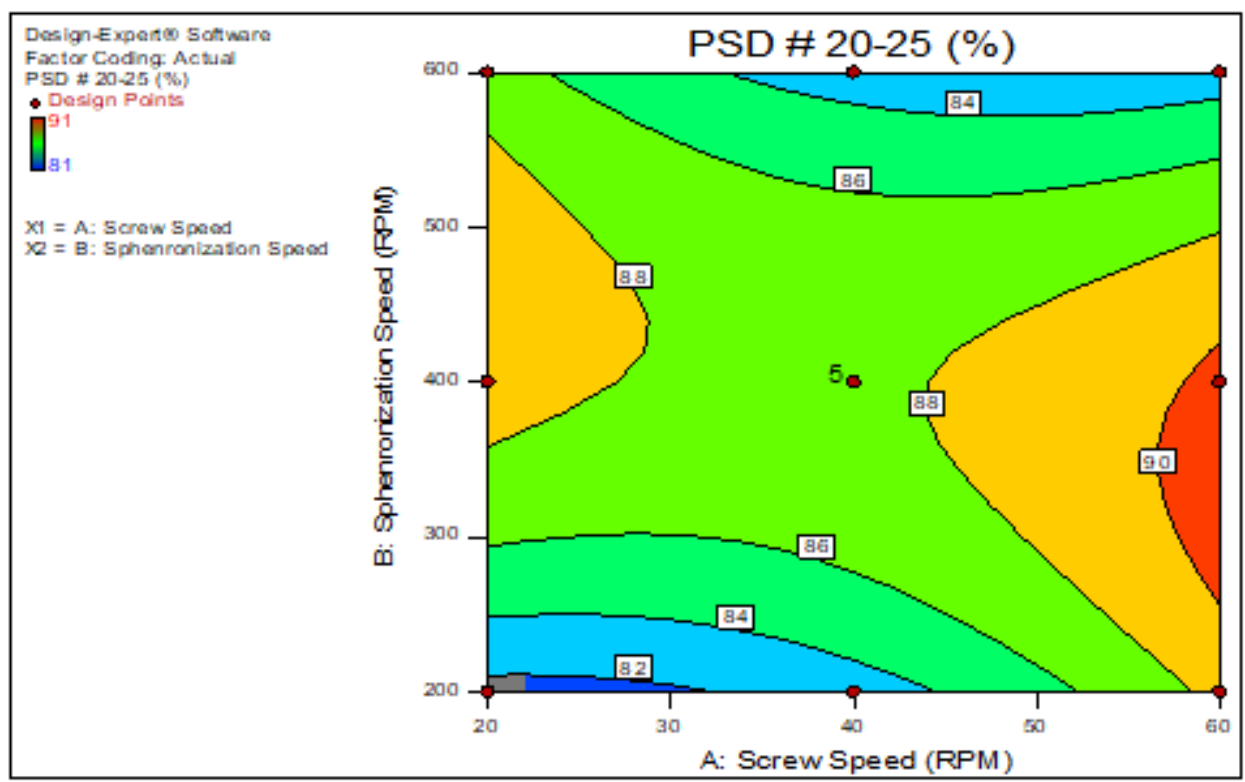

Figure 7: Contour plot of PSD \#20-25\% 


\section{International Journal of Science and Research (IJSR) \\ ISSN (Online): 2319-7064}

Index Copernicus Value (2015): 78.96 | Impact Factor (2015): 6.391

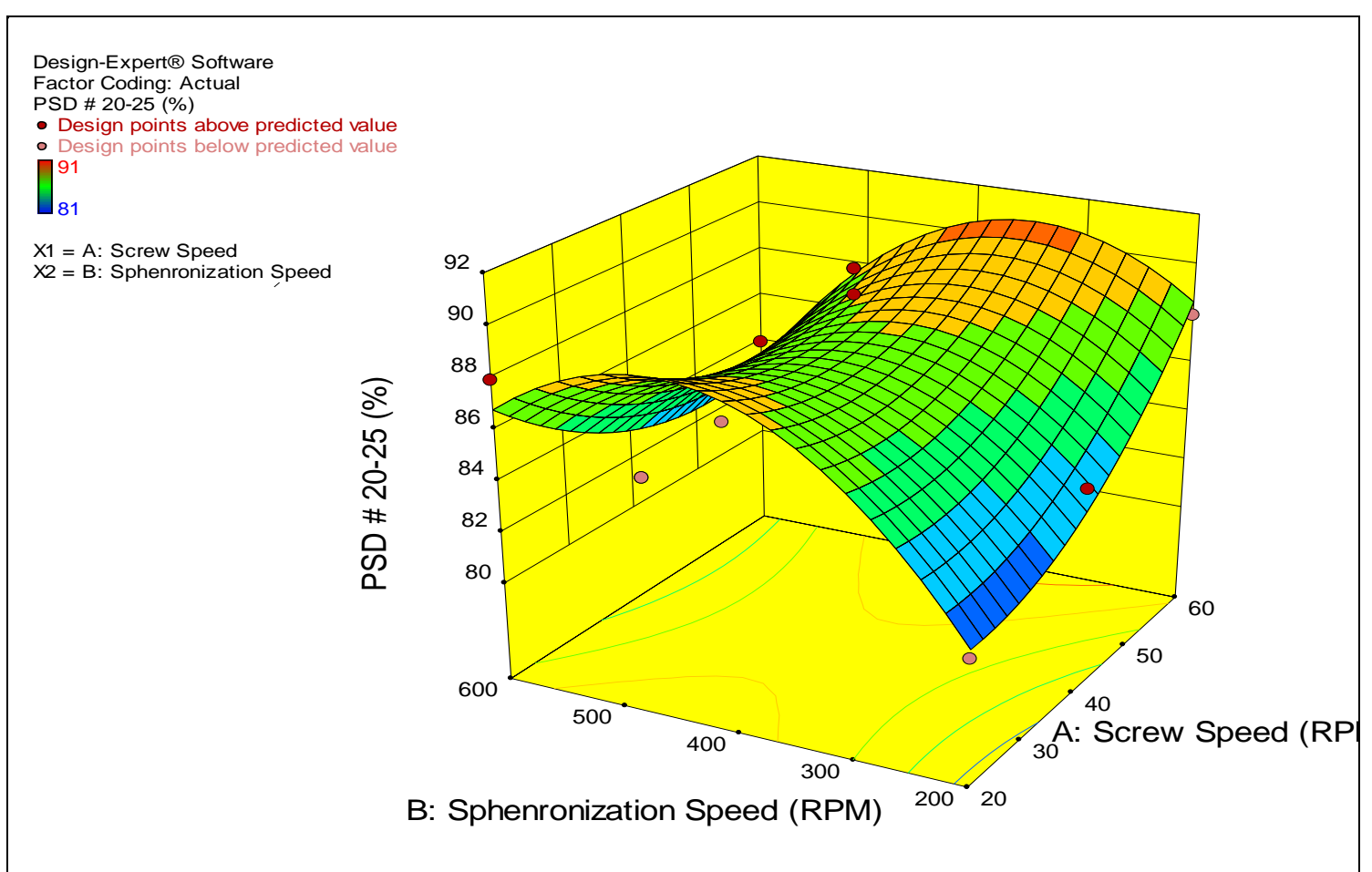

Figure 8: 3 D Plot of PSD \# 20-25

DoE statistical analysis demonstrated that the impact of all factors (in the studied range) on the response studied was significant. Based on the observation suggested model for PSD above \# 20-25 is Quadratic. The Contour plot and 3 D plot showing impact of Factor B (Spheronization speed).
The Spheronization speed and screw speed showing Quadratic interactions on the response Particle Size distribution above \# 20-25.

\section{Response 5: PSD Below \# 25}

Table 14: Summary of Model selection for particle size below \# 25

\begin{tabular}{|c|c|c|c|c|c|}
\hline \multicolumn{7}{|c|}{ Summary (detailed tables shown below) } \\
\hline & Sequential & Lack of Fit & Adjusted & Predicted & \\
\hline Source & p-value & p-value & R-Squared & R-Squared & \\
\hline Linear & 0.0015 & 0.3929 & 0.6715 & 0.5303 & Suggested \\
\hline 2FI & 0.3007 & 0.3915 & 0.6781 & 0.5072 & \\
\hline Quadratic & 0.0794 & 0.7488 & 0.7993 & 0.6062 & \\
\hline Cubic & 0.6012 & 0.6174 & 0.7708 & 0.1142 & Aliased \\
\hline
\end{tabular}

Suggested model for response PSD \#20 min is Linear.

Table 15: ANOVA for particle size below \# 25

\begin{tabular}{|c|c|c|c|c|c|c|}
\hline \multicolumn{7}{|c|}{ Response 5 : PSD Below\# 25} \\
\hline \multicolumn{7}{|c|}{ ANOVA for Response Surface Linear model } \\
\hline \multicolumn{7}{|c|}{ Analysis of variance table [Partial sum of squares - Type III] } \\
\hline Source & $\begin{array}{l}\text { Sum of } \\
\text { Squares }\end{array}$ & $\begin{array}{l}\text { Degre of } \\
\text { freedom }\end{array}$ & $\begin{array}{l}\text { Mean } \\
\text { Square }\end{array}$ & $\begin{array}{c}\mathrm{F} \\
\text { Value }\end{array}$ & $\begin{array}{l}\text { p-value } \\
\text { Prob }>F\end{array}$ & \\
\hline Model & 140.3333 & 2 & 70.1667 & 13.2647 & 0.0015 & Significant \\
\hline A-Screw Speed & 0.1667 & 1 & 0.1667 & 0.0315 & 0.8627 & \\
\hline B-Sphenronization Speed & 140.1667 & 1 & 140.1667 & 26.4978 & 0.0004 & \\
\hline Residual & 52.8974 & 10 & 5.2897 & & & \\
\hline Lack of Fit & 35.6974 & 6 & 5.9496 & 1.3836 & 0.3929 & Not Significant \\
\hline Pure Error & 17.2000 & 4 & 4.3000 & & & \\
\hline Corrected Total & 193.2308 & 12 & & & & \\
\hline
\end{tabular}

The Model F-value of 13.26 implies the model is significant. There is only a $0.15 \%$ chance that an F-value this large could occur due to noise. Values of "Prob > F" less than 0.0500 indicate model terms are significant. In this case B is a significant model term. Values greater than 0.1000 indicate the model terms are not significant. The "Lack of Fit F-value" of 1.38 implies the Lack of Fit is not significant relative to the pure error. There is a $39.29 \%$ chance that a "Lack of Fit F-value" this large could occur due to noise.

\begin{tabular}{|l|l|l|l|}
\hline Std. Dev. & 2.2999 & R-Squared & 0.7262 \\
\hline Mean & 6.4615 & Adj R-Squared & 0.6715 \\
\hline C.V. \% & 35.5944 & Pred R-Squared & 0.5303 \\
\hline PRESS & 90.7583 & Adeq Precision & 9.0509 \\
\hline
\end{tabular}


International Journal of Science and Research (IJSR)

ISSN (Online): 2319-7064

Index Copernicus Value (2015): 78.96 | Impact Factor (2015): 6.391

\begin{tabular}{|c|c|}
\hline \multicolumn{2}{|l|}{ Final Equation in Terms of Coded Factors } \\
\hline PSD Below\# 25 & $=$ \\
\hline 6.461538 & \\
\hline 0.166667 & $* \mathrm{~A}$ \\
\hline 4.833333 & $* \mathrm{~B}$ \\
\hline
\end{tabular}

\begin{tabular}{|c|c|}
\hline \multicolumn{2}{|l|}{ Final Equation in Terms of Actual Factors: } \\
\hline PSD Below\# 25 & $=$ \\
\hline-3.53846 & $*$ Screw Speed \\
\hline 0.008333 & $*$ Sphenronization Speed \\
\hline 0.024167 & \\
\hline
\end{tabular}

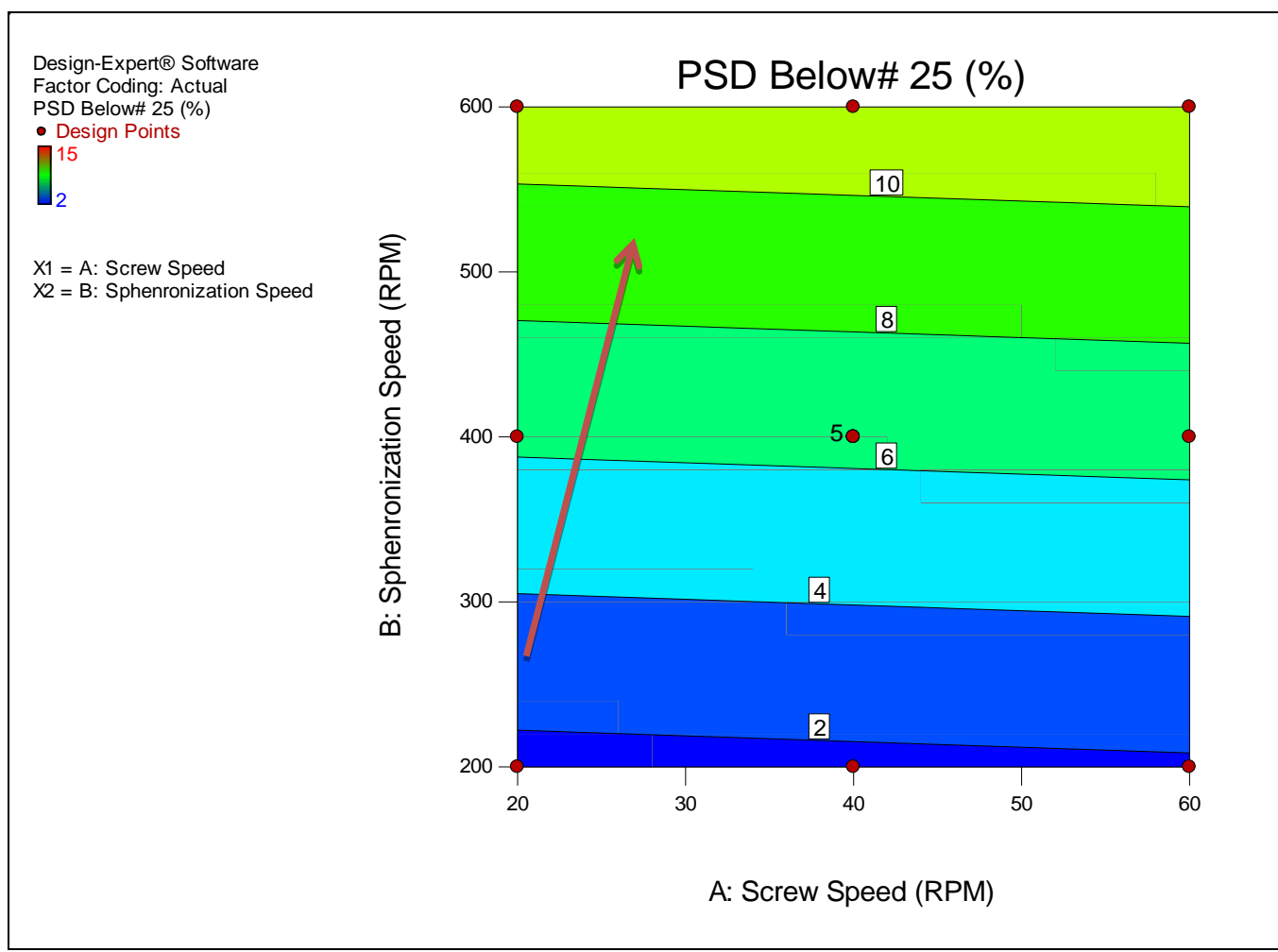

Figure 9: Contour plot of PSD below \# 25

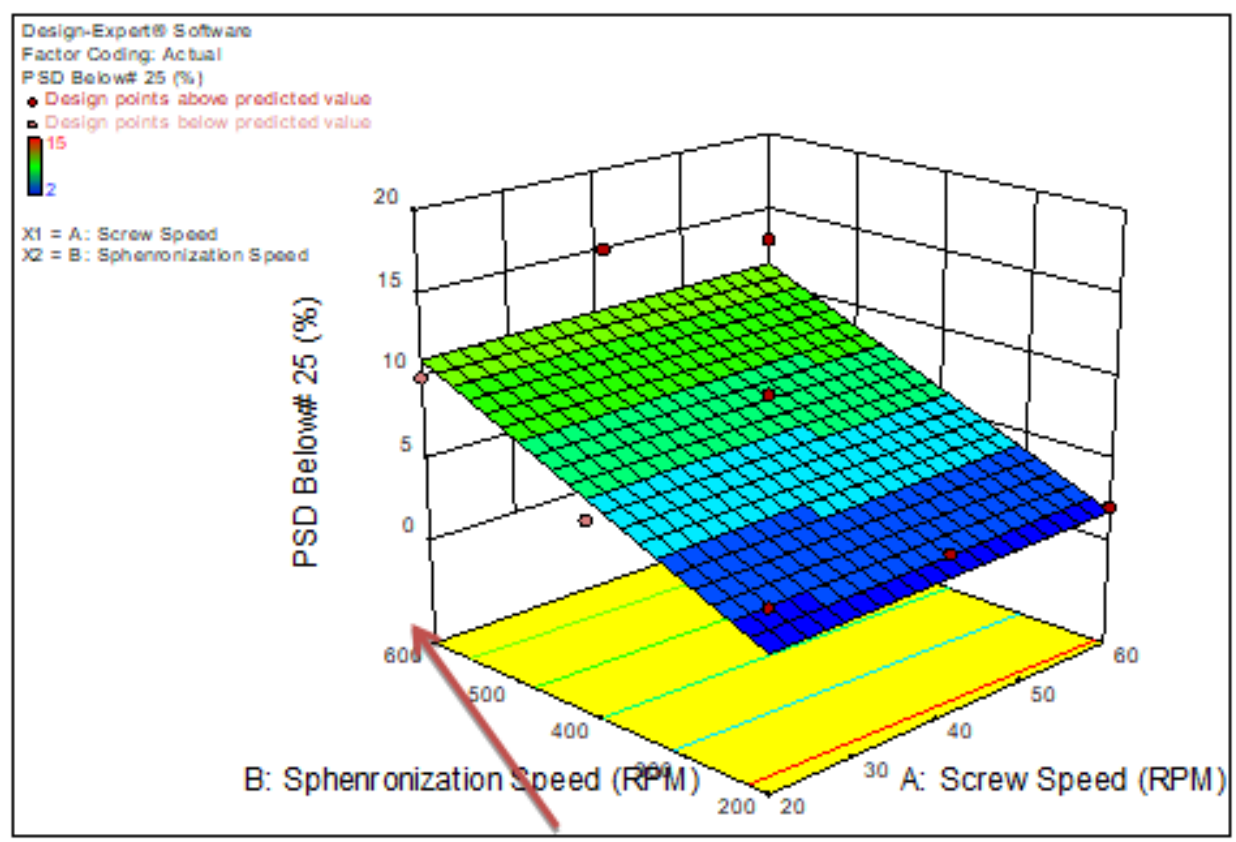

Figure 10: 3 D Plot of PSD below \# 25

DoE statistical analysis demonstrated that the impact of all factors (in the studied range) on the response studied was significant. Based on the observation suggested model for PSD below \# 25 is Linear. 


\section{International Journal of Science and Research (IJSR) \\ ISSN (Online): 2319-7064}

Index Copernicus Value (2015): 78.96 | Impact Factor (2015): 6.391

The Contour plot and $3 \mathrm{D}$ plot showing impact of Factor $\mathrm{B}$ (Spheronization speed). The Spheronization increases PSD below \#25 increases and vice versa.

\section{Optimization:}

The final ranges for factors identified through design of experiment to have optimum physical and chemical parameters need to be validated and hence an optimization study was carried out.

\begin{tabular}{|c|c|c|c|}
\hline \multicolumn{4}{|c|}{ Factor Criteria } \\
\hline Factor & Goal & Low & High \\
\hline Screw Speed & In Range & 20 & 60 \\
\hline Spheronization Speed & In Range & 200 & 600 \\
\hline \multicolumn{4}{|c|}{ Response Criteria } \\
\hline Response & Goal & Low & High \\
\hline Aspect Ratio & In Range & 0.95 & 1.05 \\
\hline Dissolution at 30 Min & Maximum & 85 & 95 \\
\hline PSD Above \# 20 & In Range & 5 & 10 \\
\hline PSD \# 20-25 & In Range & 80 & 90 \\
\hline PSD below \# 25 & In Range & 5 & 10 \\
\hline
\end{tabular}

Contour Plot:

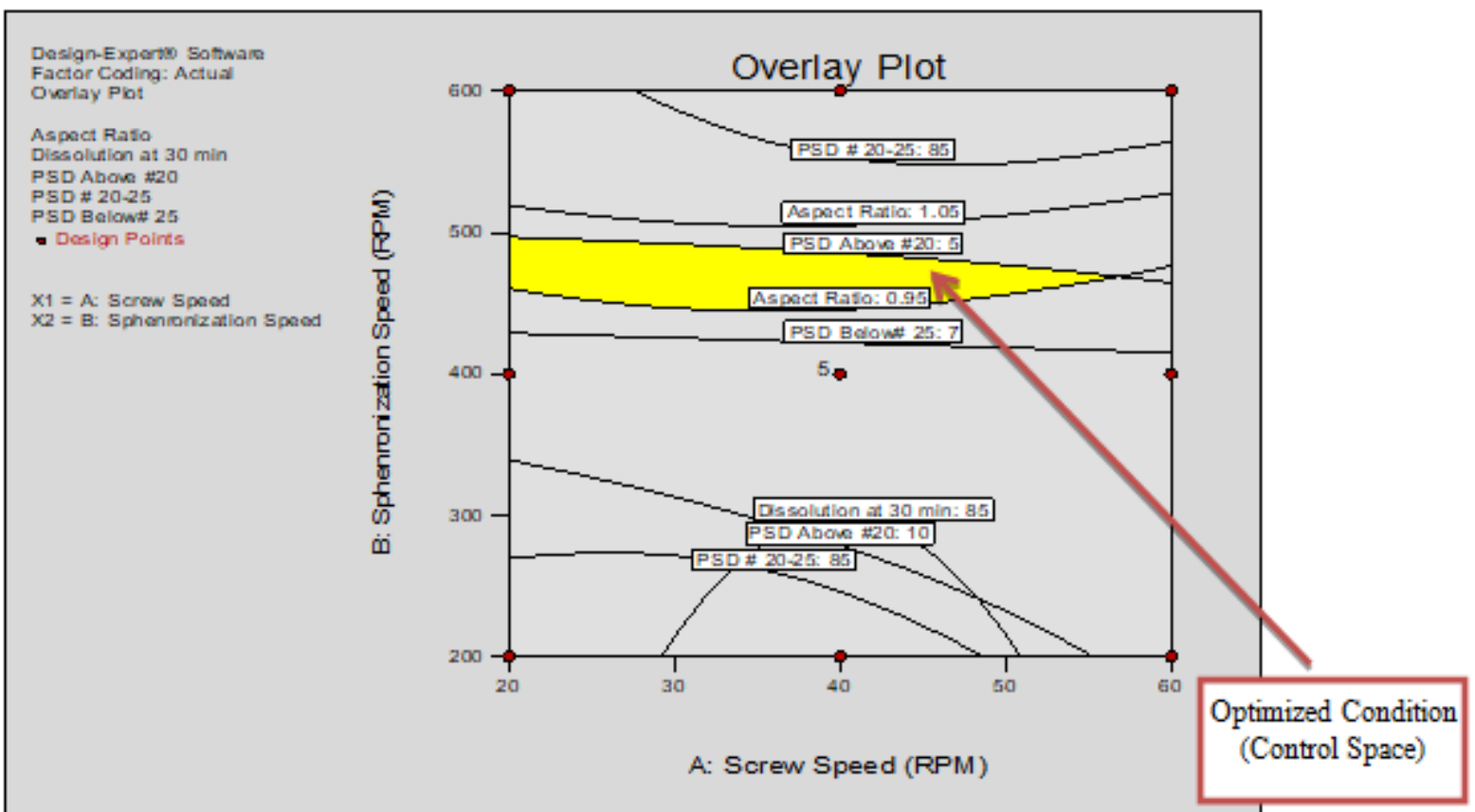

Figure 11: Design space of Screw speed and Spheronization Speed

\section{Remark:}

Yellow zone represents all responses meet predefined criteria while grey zone showing experimental region conducted through design.

\section{Verification of Design Space:}

For verification of design space, following trial to be conducted and predicted results with $95 \%$ confidence interval and compare with actual result.

\section{Trail Condition:}

\begin{tabular}{|c|c|c|}
\hline Sr. No. & Factor & Condition in RPM \\
\hline A & Screw Speed & 30 \\
\hline B & Spheronization Speed & 500 \\
\hline
\end{tabular}

\begin{tabular}{|c|c|c|c|}
\hline Response & Predicted* results & 95\% CI* & Actual Results \\
\hline Aspect Ratio & 0.95 & 0.93 & 0.94 \\
\hline Dissolution at 30 Min & 88.32 & 86.10 & 88.14 \\
\hline PSD Above \# 20 & 6.18 & 5.09 & 6.12 \\
\hline PSD \# 20-25 & 87.86 & 85.66 & 86 \\
\hline PSD below \# 25 & 7.59 & 5.75 & 7.51 \\
\hline
\end{tabular}

\section{Conclusion}

This is indicative DoE performed for determination of suitable ranges for factors and to study optimization. Based on the statistical analysis and considering the scientific rational product performance, it can be concluded that the Factor A (Screw Speed) and Factor B (Spheronization Speed) are the significant factor which impact on the response dissolution, aspect ratio and PSD. Contour plot above figure shows that Optimized condition (Shown in the yellow zone) there is interaction between the factor A and B. For verification of design space, verification of design space by considering one trail conducted and predicted result if aspect ratio, dissolution at $30 \mathrm{Min}$, Particle size distribution were match with actual results with $95 \%$ confidence interval. Hence we can conclude that optimization of Factor A (Screw Speed) and Factor B (Spheronization Speed) were take place at $30 \mathrm{RPM}$ and $500 \mathrm{RPM}$ respectively.

\section{Future Scope}

It is of immense importance to build the quality in the product by design itself rather than testing into it upon completion. Current study outlines the importance of various factors that affects the final output of any product. This study is carried out at lab scale and it becomes imperative to check the impact of proposed parameters derived from study on a larger /commercial scale. In future the success of this study will ensure the techno-commercial feasibility of product designed with the approach studied. 


\section{International Journal of Science and Research (IJSR) \\ ISSN (Online): 2319-7064}

Index Copernicus Value (2015): 78.96 | Impact Factor (2015): 6.391

\section{References}

[1] T.M. Allen and P.R. Cullis Drug Delivery Systems: Entering the Mainstream Science303 2004 1818-1822

[2] K. Kostarelos Rational design and engineering of delivery systems for therapeutics: biomedical exercises in colloid and surface science Adv. Colloid Interface Sci. 106,2003 147-168

[3] Á. Orbán, J. Dredán, R. Zelkó, I. Antal, I. Rácz: Effect of the plasticizer content on the dissolution characteristics of Eudragit coated Metoprolol pellets Die Pharmazie 53(11), 802-803, (1998) IF: 0,419

[4] http://phd.sote.hu/mwp/phd_live/vedes/export/orban.d.p df

[5] Orbán Á.: A magyargyógyszeriparmúltja, jeleneéslehetőségei.Gyógyszerészet, 43, 453-458, (1999).

[6] AfifaBathool et al Pelletization as a key tool for oral drug delivery: A review Journal of Pharmacy Research 2011,4(10),3282-3286

[7] R.Manivannan et al. Multiparticlate drug delivery systems : Pellet \&pelletization technique Drug Invention Today 2010, 2(5),233-237

[8] Rowe R.C. Spheronization: a novel pill-making process. Pharm Int 1985; 6: 119- 123.

[9] Devices GSI. Pharmaceutical Pelletization Technology. Vol. 37. Marcel Dekker Inc.; 1989, pp. 30-100.

[10] Steckel H, Mindermann-Nogly F. Production of chitosan pellets by extrusion spheronization. Eur $\mathrm{J}$ Pharm Biopharm 2004; 57: 107-13.

[11] Newton J.M. 1996: Spheronization, in Swarbrick, J. and Boylan, J.C., ed., Encyclopedia of pharmaceutical technology, Marcel Dekker, inc., New York.

[12] Erkoboni, D. 1997: Extrusion-Spheronization as a granulation technique, in Parikh, D.M., ed., Handbook of pharmaceutical granulation technology, Marcel Dekker, Inc., New York.

[13] Swarbrick J. Encyclopedia of Pharmaceutical technology, 11: 369.

[14] Devices GSI. Pharmaceutical Pelletization Technology. Vol. 37. Marcel Dekker Inc.; 1989, pp. 30-100.

[15]Hicks DC, Freese HL. Extrusion and spheronizing equipment in pharmaceutical pelletization technology. Marcel Dekker Inc. 1989, pp.71.

[16] Brabander C de, Vervaet C, Remon JP. Development and evaluation of sustained release mini-matrices prepared via hot melt extrusion. JControlled Release 2003; 89(2):235-247.

[17]Zhang F, McGinity JW. Properties of sustained-release tablets prepared by hot-melt extrusion. Pharmaceut Dev. Tech. 1999; 4(2):241-250.

[18] Prodduturi S, Manek RV, Kolling WM, Stodghill SP, Repka MA. Solidstate stability and characterization of hot-melt extruded poly (ethylene oxide) films. J Pharm Sci. 2005; 94(10):2232-2245.

[19] Mididoddi PK, Prodduturi S, Repka MA. Influence of tartaric acid on the bioadhesion and mechanical properties of hot-melt extruded hydroxypropyl cellulose films for the human nail. Drug Dev Ind Pharm. 2006; 32:1059-1066.

[20]Repka MA, McGinity JW. Bioadhesive properties of hydroxypropylcellulose topical films produced by hot- melt extrusion. J Controlled Release. 2001; 70(3):341351.

[21] Andrews, Gavin P.J, David S, Osama AM, Daniel NM, Mark.S. Hot Melt Extrusion: An Emerging Drug Delivery technology. Pharmaceutical Technology Europe 2009; 21(1):24-27.

[22] Rahman et al., Hot Melt Extrusion and Freeze Pelletization: Better Alternative For Drugs Having Stability Problem due to Presence of Water. IJPSR, 2010; Vol. 1 (11): 22-31

[23] Chokshi R and Zia H: Hot melt extrusion technique: a review, Iranian J Pharm Res 2004; 3: 3-16.

[24] Schafer T, Holm P and Kristensen HG: Melt granulation in a laboratory scale high shear mixer, Drug Dev Ind Pharm 1990; 16(8):1249-1277.

[25] Devices GSI. Pharmaceutical Pelletization Technology. Vol. 37. Marcel Dekker Inc.; 1989, pp. 30-100. 